\title{
Victims and Perpetrators of Intimate Partner Violence Among Sexually Active Youth in a Community With a High HIV Prevalence in Western Kenya
}

\author{
Barbara Burmen, ${ }^{a}$ George Olilo, ${ }^{a}$ Ester M Makanga ${ }^{a}$ \\ ${ }^{a}$ Centre for Global Health Research, Kenya Medical Research Institute, Kisumu, Kenya \\ Correspondence to Barbara Burmen (drburmen@gmail.com).
}

\begin{abstract}
Background: Physical intimate partner violence (IPV) is an important risk factor for sexually transmitted infections, including HIV. We set out to determine the prevalence and correlates of IPV among youth aged 15 to 24 years - in a community with a high HIV prevalence - with a view to recommending strategies to address IPV.

Methods: We analysed data from an HIV seroprevalence survey, which included participants aged 13 years and above and was conducted between November 2012 and December 2014 in Gem Subcounty, Siaya County, Western Kenya. Participants between 15 and 24 years old (youth) were described as "perpetrators of IPV" if they had done anything to physically hurt their sexual partners in the previous year and as "victims of IPV" if they had been physically hurt by a sexual partner in the same timeframe. Logistic regression was used to determine factors associated with being either a victim or perpetrator of IPV.

Results: Of 1,957 participants included in the analysis, $142(7 \%)$ were victims of IPV, and $77(4 \%)$ were perpetrators of IPV. Victims were likely to be women (adjusted odds ratio [AOR] 7.9;95\% Cl, 3.6 to 17.5), in a relationship or married (AOR $3.1 ; 95 \% \mathrm{Cl}, 1.8$ to 5.4), and to have had multiple lifetime sexual partners. Victims of IPV were also more likely than not to have been subjected to sexual violence in the past (AOR 1.9;95\% Cl, 1.0 to 3.4) or recently (AOR 3.9; $95 \% \mathrm{Cl}, 2.2$ to 6.8). Perpetrators were likely to be men (AOR 2.1; $95 \% \mathrm{Cl}, 1.2$ to 3.7), with 5 or more lifetime sexual partners (AOR 2.8; 95\% Cl, 1.3 to 6.3), and to have committed sexual violence recently (AOR 2.9; $95 \% \mathrm{Cl}, 1.1$ to 7.7). Conclusion: There was a high prevalence of IPV among sexually active youth in this rural community. Study participants were recurrent victims or perpetrators and reported behaviours that put them at risk of HIV acquisition. Health programmes should screen for IPV victims and perpetrators using identified characteristics. Existing policies regarding gender-based violence should be enforced, and future research should focus on the impact of IPV prevention programmes.
\end{abstract}

\section{INTRODUCTION}

I n 2017, 1.8 million new HIV infections and 36.9 million people living with HIV were reported worldwide. Two-thirds of those new infections and 25.7 million of the people living with HIV were from in sub-Saharan Africa. ${ }^{1}$ Youth aged 15 to 24 years accounted for $42 \%$ of new HIV infections in people aged 15 years and older. In 2012, globally, young women aged 15 to 24 years had HIV infection rates twice as high as young men and accounted for $22 \%$ of all new HIV infections, including $31 \%$ of new infections in sub-Saharan Africa. ${ }^{2}$

Globally, $10 \%$ to $69 \%$ of women report having been assaulted by an intimate male partner. ${ }^{3}$ Physical intimate partner violence (IPV) is an important risk factor for sexually transmitted infection and HIV transmission. ${ }^{4,5}$ Research has shown that interrelationships between IPV and other forms of violence also increase the risk of HIV transmission. ${ }^{6}$ In Zambia, among ever-married women, those who had experienced any form of IPV were twice as likely to be HIV-positive compared with those who had not experienced IPV. ${ }^{7}$ IPV has also been linked to poor HIV testing and antiretroviral therapy uptake ${ }^{8}$ as well as poor antiretroviral therapy outcomes. ${ }^{9}$

In 2015, HIV acquisition among youth aged 15 to 24 - who formed $20 \%$ of the population - constituted more than half of all new HIV infections and one-fifth of people living with HIV in Kenya. ${ }^{10}$ Low HIV testing uptake 
and linkage to care rates have been shown among children, adolescents, and young adults in Kenya. ${ }^{11}$ Combating IPV is likely to reduce the spread of HIV and improve the uptake of HIV health services. The general strategy to combat IPV can be either preventative or therapeutic ${ }^{6}$; however, this requires identifying actual or potential victims and perpetrators of IPV.

We set out to determine the prevalence of IPV among youth within the Kenya Medical Research Institute and U.S. Centers for Disease Control and Prevention (KEMRI/CDC) Health and Demographic Surveillance Area (HDSA). We also aimed to determine factors that correlate with IPV, with a view to recommending strategies to prevent and address IPV in the Western Region of Kenya, an area with a high HIV burden.

\section{METHODS}

\section{Study Design and Setting}

KEMRI/CDC's research and public health collaboration conducted a cross-sectional survey within its HDSA in Gem Subcounty, Siaya County, Western Kenya, between January 2013 and February 2014. The KEMRI/CDC HDSA has a population of approximately 218,376 people living in 70,505 households within 3 regions: 61,707 in Asembo, 78,874 in Gem, and 77,795 in Karemo. As there had been minimal research and intervention activities rolled out in Gem, it was an ideal community for assessing the effects of new interventions. Gem's population is culturally homogeneous and survives on subsistence farming and fishing; over $95 \%$ are members of the Luo tribe, and $50 \%$ are younger than 13 years of age. Detailed descriptions of the study design and methods are described in our other papers. ${ }^{12,13}$ The survey aimed to evaluate HIV risk behaviours, HIV serostatus, and HIV prevention interventions.

\section{Study Population}

The study population in the main survey included all persons aged 13 years of age or older, who lived within the selected compounds, had spent the previous night in the designated households, and consented to participate in the study. Individuals who did not consent to participate were excluded. We restricted our analysis to youth aged 15 to 24 years, ${ }^{14}$ who had been sexually active in the past year, and had answered questions about ever having been a victim or perpetrator of IPV.

\section{Sampling}

Of 14,501 compounds registered in Gem in 2010, we randomly selected 6,000 , partly by community sampling (750 households) via a participatory community event and partly by computer-generated statistical sampling $(5,250$ households) conducted by the HDSA data team. The study statistician randomly sampled the remaining compounds using a computer. Details of these sampling methods are described by Phillips-Howard et al. ${ }^{15}$

\section{Data Collection}

For all participants, interview topics included participant demographics, sexual behaviour, and utilisation of HIV health services. From data collected during the survey, we extracted a database of persons aged 15 to 24 to address our research questions.

\section{Outcome Variable Definitions}

For this analysis, we adapted the United Nations definition of IPV to include only 'physical harm from a current or former intimate partner'. ${ }^{16}$ Participants were described as "victims of IPV" if they answered "yes" to the question, "Has any of your sexual partners, in the last year, hit, slapped, kicked, or done anything else to hurt you physically?' Participants were identified as "perpetrators of IPV" if they answered in the affirmative to the question, 'Have you, in the last year, hit, slapped, kicked, or done anything else to physically hurt any of your sexual partners?'

\section{Definitions of Independent Variables of Interest}

A sexual partner was described as a "recent sex partner" if he or she had been a sexual partner of the interviewee within 1 year preceding the interview. Study participants were described as "single" if they reported not having a romantic or cohabiting partner or spouse at the time of interview, including if they were separated or widowed. "In a relationship or married" was defined as participants who were in a monogamous or polygamous relationship, cohabiting, or married.

Participants were characterised as having ever been subjected to "sexual violence in the past" if they answered "yes" to the question, 'Have you ever been forced to have sex?' Participants who had been subjected to "sexual violence recently" were those who answered in the affirmative to the question, 'In the last 12 months, has partner $\mathrm{X}$ forced you to have sex?' Depending on the interviewee's sexual history, "partner X" referred to any of the interviewee's 3 most recent sexual partners in the year preceding the interview. Conversely, participants had committed "sexual violence recently" if they answered affirmatively to the question, 'In the last 12 months, have you forced any of your sexual partners to have sex?'

Participants were described as ever having experienced "a condom error" with a recent sexual partner if they answered "yes" to the any of the following questions: 'While using condoms with partner X, did you ever put on the condom after you had already started having sexual intercourse?', 'Did you ever take off the condom before you were finished having sexual intercourse?', 'Did the condom you were using ever slip off during sex or while pulling out?', or 'Did the condom you were using ever break or leak during sex or while pulling out?' 


\section{Data Analysis}

Proportions were used to describe participant characteristics. Chi-square or Fisher's exact tests were used to compare participants according to their history of having been subjected to or having perpetrated IPV. Logistic regression was used to determine factors associated with being either victims or perpetrators of IPV. Variables that attained a $P$ value less than .2 in the univariate analysis were included in the multivariate logistic regression model. Using backward elimination criteria, variables that had a $P$ value less than .1 were retained in the multivariate model. Variables that had a $P$ value less than .05 were considered significant. Crude odds ratios, which explained the relationship between a given variable and the outcome, were reported. Adjusted odds ratios (AORs), which included the influence of other variables on the outcome, were also reported. All estimates were reported with $95 \%$ confidence intervals (CIs). ${ }^{17}$ Analysis was done using Statistical Analysis Software (SAS), version 9.2 (SAS Institute Inc., Cary, NC, USA).

\section{Ethical Approval}

Permission to conduct this study was granted by the Kenya Medical Research Institute Ethics Review Committee (SSC No. 1801).

\section{RESULTS}

\section{Participant Selection}

Of 14,116 interviewees, 5,225 (37\%) were youths, $1,992(38 \%)$ of whom had been sexually active in the previous 12 months. Among these, 1,957 (98\%) answered questions regarding having ever been subjected to or having ever perpetrated IPV (Figure).

\section{Participant Characteristics}

Of the 1,957 participants included in the analysis, the majority were aged 19 to 22 years $(n=1,002 ; 51 \%)$, female $(n=1,174,60 \%)$, single $(n=993,51 \%)$, had primary or below primary-level education $(n=1,349,69 \%)$, and engaged in some form of employment $(n=1,054,54 \%)$.

At the time of their respective interviews, participants frequently reported having had 2 lifetime sexual partners $(\mathrm{n}=563,31 \%)$ and 1 recent sexual partner $(\mathrm{n}=1,687,86 \%)$. Some participants reported having a sexual partner who had other concurrent sexual partners $(n=267,14 \%)$ or had newly acquired other sexual partners $(n=233,12 \%)$. Regarding experience with sexual violence, 131 (7\%) participants reported that they had been subjected to sexual violence recently, $134(7 \%)$ had been subjected to sexual violence in the past, and $48(3 \%)$ had recently committed sexual violence.

The majority of participants had previously used a condom during sexual intercourse $(n=1,239,63 \%)$ or had at some point asked a sexual partner to use a condom $(n=996$,
FIGURE. Participant Selection

14,116 participants interviewed

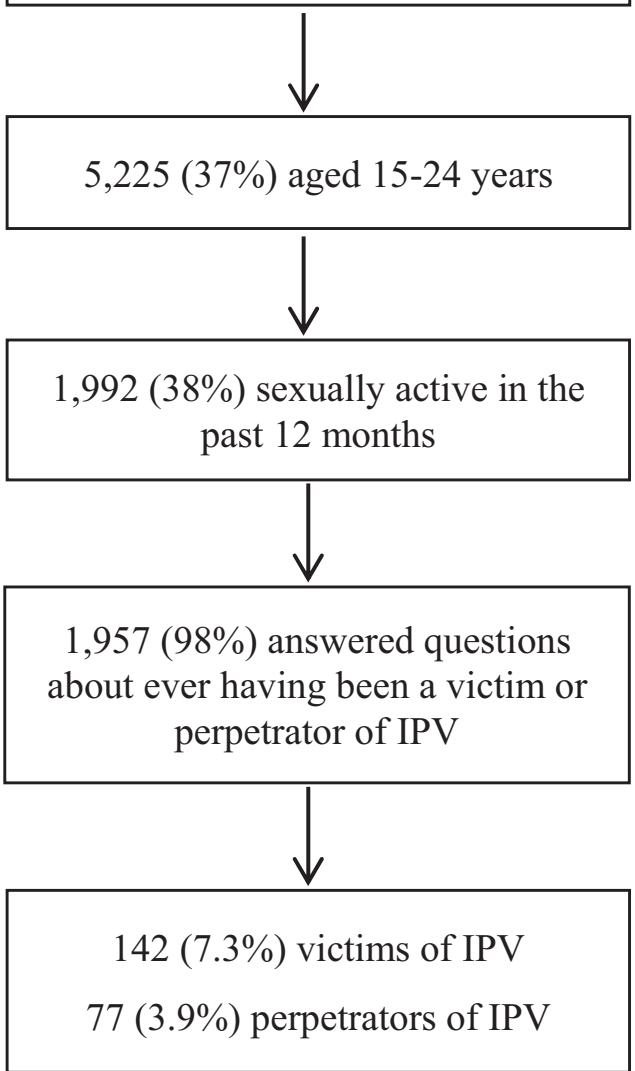

Abbreviation: IPV, intimate partner violence.

$51 \%)$. Conversely, less than half $(n=842,43 \%)$ had used condoms during their most recent sexual intercourse, and $205(11 \%)$ reported having experienced condom errors with a recent sexual partner (Table 1).

In the year preceding the survey, a minority of participants reported that they themselves $(n=45,2 \%)$ or their sexual partners $(n=51,3 \%)$ had taken drugs or mind-altering substances. Few participants reported having consumed alcohol before sex or being drunk during sex $(n=67,3 \%)$ or having had sexual partners who had consumed alcohol before or been drunk during sexual intercourse $(n=77,4 \%)$ (Table 1).

\section{Victims of Intimate Partner Violence}

Of the 1,957 participants, $142(7 \%)$ reported having ever been victims of IPV. Of the 142 past victims of IPV, $29(22 \%)$ 
TABLE 1. Characteristics of Youth Interviewed in Gem, Siaya County, Western Kenya, 2013-2014 (N=1,957)

Characteristics $n(\%)$

Age group, years

$15-18$

$410(21)$

$19-22$

$1,002(51)$

23-24

$546(28)$

Gender

Male

$784(40)$

Female

$1,174(60)$

Marital status

Single ${ }^{a}$

$993(51)$

964 (49)

In a relationship or married

Education level

Primary or below

$1,349(69)$

Above primary

$608(31)$

Occupation

Employed

$1,054(54)$

Unemployed

$905(46)$

Lifetime number of sex partners ${ }^{b}$

1

2

449 (25)

$563(31)$

$548(30)$

$264(14)$

5 and above

Number of sex partners in the last 12 months

1

$1,687(86)$

$268(14)$

2 and above

Primary sexual partner has other partners

Yes

$267(14)$

No

$1,692(86)$

Primary sexual partner recently acquired a new partner

Yes

No

$1,726(88)$

Subjected to sexual violence in the past ${ }^{c}$

Yes

$134(7)$

$1,825(93)$

Subjected to sexual violence recently ${ }^{d}$

Yes

$131(7)$

No

$1,828(93)$
TABLE 1. Continued

\begin{tabular}{lc}
\hline Characteristics & $\mathbf{n}(\%)$ \\
\hline Committed sexual violence recently & \\
Yes & $48(3)$ \\
No & $1,911(97)$
\end{tabular}

Ever used a condom

Yes

$1,239(63)$

No

$720(34)$

Ever asked partner to use a condom

Yes

$996(51)$

No

963(49)

Used a condom during last sexual intercourse

Yes

$842(43)$

No

$1,117(57)$

Experienced condom error in the past

12 months

Yes

205 (11)

No

1,754 (89)

Ever consumed alcohol before sex or been drunk during sex

Yes

No

$1,892(97)$

Partner ever consumed alcohol before sex or been drunk during sex

Yes

No

$1,882(97)$

Used drugs or mind-altering substances in the past year

Yes

No

$1,914(98)$

Partner used drugs or mind-altering substances in the past year

Yes

No

$1,908(97)$

a Includes 32 participants who were either divorced or widowed.

${ }^{\mathrm{b}}$ Responses missing for 135 respondents.

c Participants were characterised as having ever experienced 'sexual violence in the past' if they answered "yes" to the question, 'Have you ever been forced to have sex?'

d Participants were characterised as having been subjected to 'sexual violence recently' if they answered in the affirmative to the question, 'In the last 12 months has partner $X$ forced you to have sex?'

e Participants were characterised as having ever committed sexual violence if they answered "yes" to the question, "In the last 12 months have you forced any of your sex partners to have sex?' 
reported having been subjected to sexual violence within the 12 months before being interviewed, and 40 (31\%) said they had been subjected to sexual violence recently (AOR 3.9; $95 \%$ CI, 2.2 to $6.8 ; P<.01)$. Victims of IPV were more likely to be female $(n=131,92 \%)$ than male $(n=11,8 \%$; AOR 7.9; $95 \%$ CI, 3.6 to $17.5 ; P<.01)$, and to be in a relationship or married $(n=118,83 \%)$ than single $(n=24,17 \%$; AOR 3.1; $95 \% \mathrm{CI}, 1.8$ to $5.4 ; P<.01)$. Overall, $11 \%$ of females were victims of IPV, compared to $1 \%$ of males (Table 2 ).

According to 135 available records, victims of IPV were also more likely to have had either 2 ( $n=34,25 \%$; AOR 1.2; $95 \%$ CI, 1.9 to 8.4$), 3$ to 4 ( $n=59,43 \%$; AOR 2.1; 95\% CI, 1.2 to 3.9$)$, or 5 or more $(n=25,19 \%$; AOR $4.0 ; 95 \% C I$, 1.9 to 8.4$)$ lifetime sexual partners than to have had $1(n=17$, $13 \%)$ lifetime sexual partner $(P<.01)$. Furthermore, among victims of IPV, $32(23 \%)$ had primary sexual partners who had additional concurrent partners, and 39 (27\%) had primary partners who had recently acquired new sexual partners. There were $29(20 \%)$ victims of IPV who reported having been subjected to sexual violence in the past, compared with $113(80 \%)$ who had not been subjected to sexual violence more than 12 months prior (AOR 1.9; 95\% CI, 1.0 to $3.4 ; P<.01)$.

\section{Perpetrators of Intimate Partner Violence}

Of the 1,957 participants, 76 (4\%) reported having ever been perpetrators of IPV. Perpetrators of IPV were more likely to be male $(n=52,68 \%)$ than female $(n=24,32 \%$; AOR 2.1; $95 \%$ CI, 1.2 to $3.7 ; P<.01)$. Among 66 available records, perpetrators of IPV were more likely to have had 5 or more $(\mathrm{n}=27,41 \%)$ lifetime sexual partners than $\mathrm{l}(\mathrm{n}=10,15 \%$; AOR 2.8; $95 \%$ CI, 1.3 to $6.3, P<.01$ ) lifetime sexual partner. Among the 76 participants who identified themselves as perpetrators of IPV in the previous year, 7 (9\%) also reported committing sexual violence within the same period, compared to $69(91 \%)$ who reported that they had not recently committed sexual violence (AOR 2.9; $95 \%$ CI, 1.1 to 7.7 ; $P=.02$ ). Overall, $7 \%$ of males and $2 \%$ of females identified themselves as perpetrators of IPV (Table 3).

\section{DISCUSSION}

Among the 1,957 sexually active youths in our study population, $7 \%$ were victims and $4 \%$ were perpetrators of IPV. The prevalence of IPV was lower than what was found in a 2005 survey conducted in 10 countries by the World Health Organization. That study revealed that $13 \%$ to $61 \%$ of women who had ever been in an intimate partnership had been subjected to physical violence by a partner. ${ }^{6}$ A Kenyan national survey, conducted in 2014, found that one-fifth of all women aged 15 years and older had experienced some form of physical violence. ${ }^{18}$ It is important to highlight that our study sample was limited to youth aged 15 to 24 years, as opposed to other studies that may have included broader age ranges. Nevertheless, younger individuals have been shown to have higher rates of IPV, ${ }^{19}$ and intervening at this stage is therefore likely to reduce the chances of lifetime victimisation and perpetration, which increase the risk of HIV transmission. ${ }^{5}$

While being interviewed, victims of IPV - who were mostly female and of low educational status - were likely to be in a current relationship with a partner whose abuse qualified the partnered individuals to be a victim and perpetrator of IPV, according to the study definitions. In the 2014 Kenya Demographic and Health Survey, more than half $(57 \%)$ of women who had ever experienced physical violence stated that the perpetrator was the current spouse. ${ }^{19}$ Similar results have been reported in India and South Africa. ${ }^{20,21}$ This could be related to a high level of economic dependency by women on men, ${ }^{16}$ which may make many women reluctant to report IPV. ${ }^{22}$ In Uganda, a decrease in IPV has been associated with the empowerment of women, providing evidence to support the importance of education and delayed partnering for young women. ${ }^{19,23}$

Our assessment corroborated the presumption that perpetrators are usually male. In the literature, the perpetrators of IPV are typically men living in communities where violence is routinely used to resolve problems. Perpetrators in such communities often feel their male identity being challenged by factors related to poverty. ${ }^{16}$ Although our study found higher rates of IPV perpetration among males, other sources report similar rates of IPV perpetration by men and women, with women less likely than men to commit severe violence. IPV inflicted by women on men is likely to be underreported due to social desirability bias, and limited information exists in the literature about male victims of IPV. ${ }^{19}$

Many victims and perpetrators reported having had more than 1 lifetime sexual partner and having been subjected to or having committed IPV over a duration that extends earlier than the preceding 12 months considered in the study definition of IPV. In India ${ }^{20}$ and South Africa, ${ }^{21}$ women who reported IPV were more likely to have been abused in the past. As both IPV 5 and multiple sex partners ${ }^{24}$ are risk factors for HIV transmission, it is important to screen for IPV and provide interventions that may mitigate future occurrences. This has been the basis for second responder programmes in the United States. ${ }^{25}$

While both victims and perpetrators reported several lifetime partners, only victims reported that their partners had concurrent sexual partners. This finding is similar to reports from Togo and South Africa, where HIV-infected women who were victims of IPV also reported that their partners had multiple partners. ${ }^{26,27}$ This may be related to a common double standard regarding the sexual behaviour of men and women: while women with multiple sex partners are viewed as promiscuous, men receive praise for their sexual experiences with multiple partners. In South Africa, teenage girls stated that victims have multiple sexual partners to find solace or as a form of resistance. ${ }^{28}$ Conversely, perpetrators may seek multiple sexual partners as a form of male dominance. ${ }^{29}$ 
TABLE 2. Factors Associated With Being a Victim of Intimate Partner Violence ${ }^{a}$ in the Past Year Among Youths in Western Kenya, 2013-2014

\begin{tabular}{|c|c|c|c|c|c|}
\hline Characteristics & $\begin{array}{c}\text { Victims of IPV } \\
\text { n/Row Total } \\
\text { (\%) }\end{array}$ & $\begin{array}{c}\text { Crude } \\
\text { Odds Ratio } \\
\text { (95\% CI) }\end{array}$ & P Value & $\begin{array}{c}\text { Adjusted } \\
\text { Odds Ratioe } \\
(95 \% \mathrm{Cl})\end{array}$ & $P$ Value \\
\hline \multicolumn{6}{|l|}{ Age group, years } \\
\hline $15-18$ & $19 / 410(5)$ & Ref & \multirow[t]{3}{*}{.03} & & \\
\hline 19-22 & 73/1,001 (7) & $1.6(0.9-2.7)$ & & & \\
\hline $23-24$ & $50 / 546(9)$ & $2.1(1.2-3.6)$ & & & \\
\hline \multicolumn{6}{|l|}{ Gender } \\
\hline Male & $11 / 784(1)$ & Ref & \multirow[t]{2}{*}{$<.01$} & Ref & \multirow[t]{2}{*}{$<.01$} \\
\hline Female & $131 / 1,173(11)$ & $8.8(4.7-16.4)$ & & $7.9(3.6-17.5)$ & \\
\hline \multicolumn{6}{|l|}{ Marital status } \\
\hline Single $e^{f}$ & $24 / 969(2)$ & Ref & \multirow[t]{2}{*}{$<.01$} & Ref & \multirow[t]{2}{*}{$<.01$} \\
\hline In a relationship or married & $118 / 964(12)$ & $5.6(3.6-8.8)$ & & $3.1(1.8-5.4)$ & \\
\hline \multicolumn{6}{|l|}{ Education level } \\
\hline Primary or below & $119 / 1,349(9)$ & $2.5(1.6-3.9)$ & \multirow[t]{2}{*}{$<.01$} & & \\
\hline Above primary & $23 / 608(4)$ & Ref & & & \\
\hline \multicolumn{6}{|l|}{ Occupation } \\
\hline Employed & $90 / 1,053(9)$ & $1.5(1.1-2.2)$ & \multirow[t]{2}{*}{.02} & & \\
\hline Unemployed & $52 / 904(6)$ & Ref & & & \\
\hline \multicolumn{6}{|l|}{ Lifetime number of sex partners 9} \\
\hline 1 & $17 / 432(4)$ & Ref & \multirow[t]{4}{*}{$<.01$} & Ref & \multirow[t]{4}{*}{$<.01$} \\
\hline 2 & $34 / 563(6)$ & $1.6(0.9-2.9)$ & & $1.2(1.9-8.4)$ & \\
\hline $3-4$ & $59 / 546(11)$ & $3.1(1.7-5.4)$ & & $2.1(1.2-3.9)$ & \\
\hline 5 and above & $25 / 264$ (9) & $2.7(1.4-5.0)$ & & $4.0(1.9-8.4)$ & \\
\hline \multicolumn{6}{|c|}{ Number of sex partners in the last 12 months } \\
\hline 1 & $129 / 1,685(8)$ & $1.6(0.9-2.9)$ & \multirow[t]{2}{*}{.10} & & \\
\hline 2 and above & $13 / 268(5)$ & Ref & & & \\
\hline \multicolumn{6}{|c|}{ Primary sexual partner has other partners } \\
\hline Yes & $32 / 233(14)$ & $2.3(1.5-3.6)$ & \multirow[t]{2}{*}{$<.01$} & & \\
\hline No & $110 / 1,724(6)$ & Ref & & & \\
\hline \multicolumn{6}{|c|}{$\begin{array}{l}\text { Primary sexual partner recently acquired a new } \\
\text { partner }\end{array}$} \\
\hline Yes & $39 / 267(15)$ & $2.6(1.8-3.9)$ & \multirow[t]{2}{*}{$<.01$} & $2.7(1.7-4.2)$ & \multirow[t]{2}{*}{$<.01$} \\
\hline No & $103 / 1,690(6)$ & Ref & & Ref & \\
\hline \multicolumn{6}{|c|}{ Subjected to sexual violence in the past ${ }^{h}$} \\
\hline Yes & $29 / 105(22)$ & $4.2(2.7-6.6)$ & \multirow[t]{2}{*}{$<.01$} & $1.9(1.0-3.4)$ & \multirow[t]{2}{*}{$<.01$} \\
\hline No & $113 / 1,823(6)$ & Ref & & Ref & \\
\hline \multicolumn{6}{|c|}{ Subjected to sexual violence recently ${ }^{i}$} \\
\hline Yes & $40 / 131(31)$ & $7.4(4.9-11.3)$ & $<.01$ & $3.9(2.2-6.8)$ & $<.01$ \\
\hline No & $102 / 1,724(6)$ & Ref & & Ref & \\
\hline Committed sexual violence rec & & & & & \\
\hline Yes & $9 / 48(19)$ & $3.1(1.5-6.5)$ & $<.01$ & & \\
\hline No & $133 / 1,909(7)$ & Ref & & & \\
\hline
\end{tabular}


TABLE 2. Continued

\begin{tabular}{|c|c|c|c|c|c|}
\hline Characteristics & $\begin{array}{c}\text { Victims of IPV } \\
\text { n/Row Total } \\
(\%)\end{array}$ & $\begin{array}{c}\text { Crude } \\
\text { Odds Ratio } \\
(95 \% \mathrm{Cl})\end{array}$ & P Value & $\begin{array}{c}\text { Adjusted } \\
\text { Odds Ratio } \\
\text { (95\% Cl) }\end{array}$ & P Value \\
\hline \multicolumn{6}{|c|}{ Ever used a condom } \\
\hline Yes & $73 / 1,238(6)$ & Ref & $<.01$ & & \\
\hline No & $69 / 719(10)$ & $1.7(1.2-2.4)$ & & & \\
\hline \multicolumn{6}{|c|}{ Ever asked partner to use a condom } \\
\hline Yes & $70 / 995(7)$ & $0.9(0.7-1.3)$ & .70 & & \\
\hline No & $72 / 962(7)$ & Ref & & & \\
\hline \multicolumn{6}{|c|}{ Used a condom during last sexual intercourse } \\
\hline Yes & $37 / 842(4)$ & Ref & $<0.01$ & & \\
\hline No & $105 / 1,115(9)$ & $2.2(1.5-3.3)$ & & & \\
\hline \multicolumn{6}{|c|}{$\begin{array}{l}\text { Experienced condom error reported in the last } 3 \\
\text { months }\end{array}$} \\
\hline Yes & $15 / 204(7)$ & $1.0(0.6-1.8)$ & .90 & & \\
\hline No & $127 / 1,753(7)$ & Ref & & & \\
\hline \multicolumn{6}{|c|}{$\begin{array}{l}\text { Ever consumed alcohol before or during sex or } \\
\text { been drunk during sex }\end{array}$} \\
\hline Yes & $9 / 67(13)$ & $2.0(0.9-4.2)$ & .05 & & \\
\hline No & $133 / 1,890(7)$ & Ref & & & \\
\hline \multicolumn{6}{|c|}{$\begin{array}{l}\text { Partner ever consumed alcohol before or during } \\
\text { sex or been drunk during sex }\end{array}$} \\
\hline Yes & $21 / 77$ (27) & $5.5(3.1-9.3)$ & $<.01$ & & \\
\hline No & $121 / 1,880(6)$ & Ref & & & \\
\hline \multicolumn{6}{|c|}{$\begin{array}{l}\text { Used drugs or mind-altering substances in the past } \\
\text { year }\end{array}$} \\
\hline Yes & $1.45(2)$ & Ref & .20 & & \\
\hline No & $141 / 1,912$ (7) & $0.3(0.03-2.1)$ & & & \\
\hline \multicolumn{6}{|c|}{$\begin{array}{l}\text { Partner used drugs or mind-altering substances in } \\
\text { the past year }\end{array}$} \\
\hline Yes & 15/51 (29) & $5.8(3.1-10.9)$ & $<.01$ & & \\
\hline No & $127 / 1,906(7)$ & Ref & & & \\
\hline
\end{tabular}

aparticipants were described as "victims of IPV" if they answered "yes" to the question, 'Has any of your sexual partners, in the last year hit, slapped, kicked, or done anything else to hurt you physically?'

besponses are missing for 2 participants who did not answer questions about ever having experienced physical IPV.

'There were $142(7 \%)$ victims of IPV; the numerators in this column are the number of victims of IPV who fulfilled the criteria described in the respective rows, and the denominators are the total number of participants who fulfilled the criteria mentioned in each row.

${ }^{\mathrm{d} C}$ rude odds ratios refer to the odds of an outcome given the response status of a particular variable.

eAdjusted odds ratios are crude odds ratios adjusted after considering the influence of all other variables.

fIncludes 32 participants who were either divorced or widowed.

aResponses missing for 135 participants.

hParticipants were characterised as having ever been subjected to "sexual violence in the past" if they answered "yes" to the question, 'Have you ever been forced to have sex?'

'Participants were characterised as having been subjected to "sexual violence recently" if they answered in the affirmative to the question, 'In the last 12 months has partner X forced you to have sex?'

jParticipants were characterised as having committed "sexual violence recently" if they answered "yes" to the question, "In the last 12 months have you forced any of your sex partners to have sex?'

Abbreviations: Cl, confidence interval; IPV, intimate partner violence. 
TABLE 3. Factors Associated With Being a Perpetrator of Intimate Partner Violence ${ }^{a}$ in the Past Year Among Youths in Western Kenya, 2013-2014

\begin{tabular}{|c|c|c|c|c|c|}
\hline Characteristics & $\begin{array}{l}\text { Perpetrators of } \\
\text { IPV } n / \text { Row } \\
\text { Total (\%) }\end{array}$ & $\begin{array}{c}\text { Crude } \\
\text { Odds Ratiod } \\
\text { (95\% Cl) }\end{array}$ & $P$ Value & $\begin{array}{c}\text { Adjusted } \\
\text { Odds Ratio } \\
(95 \% \mathrm{Cl})\end{array}$ & P Value \\
\hline \multicolumn{6}{|l|}{ Age group, years } \\
\hline $15-18$ & $12 / 410(3)$ & Ref & .50 & & \\
\hline $19-22$ & $41 / 1,001(4)$ & $1.4(0.7-2.7)$ & & & \\
\hline $23-24$ & $23 / 546(4)$ & $1.5(0.7-2.9)$ & & & \\
\hline \multicolumn{6}{|l|}{ Gender } \\
\hline Male & $52 / 784(7)$ & $3.4(2.1-5.6)$ & $<.01$ & $2.1(1.2-3.7)$ & .01 \\
\hline Female & $24 / 1,149(2)$ & Ref & & Ref & \\
\hline \multicolumn{6}{|l|}{ Marital status } \\
\hline Single ${ }^{f}$ & $39 / 993(4)$ & & .92 & & \\
\hline In a relationship or married & $37 / 964(4)$ & Ref & & & \\
\hline \multicolumn{6}{|l|}{ Education level } \\
\hline Primary or below & $50 / 1,349(4)$ & $0.8(0.5-1.4)$ & .50 & & \\
\hline Above primary & $26 / 608(4)$ & Ref & & & \\
\hline \multicolumn{6}{|l|}{ Occupation } \\
\hline Employed & $51 / 1,053(5)$ & $1.8(1.1-2.9)$ & .02 & & \\
\hline Unemployed & $25 / 904(3)$ & Ref & & & \\
\hline \multicolumn{6}{|l|}{ Lifetime number of sex partners ${ }^{9}$} \\
\hline 1 & $10 / 449(2)$ & Ref & $<.01$ & Ref & $<.01$ \\
\hline 2 & $9 / 563(2)$ & $0.7(0.3-1.8)$ & & $0.7(0.3-1.6)$ & \\
\hline $3-4$ & $20 / 546(4)$ & $1.7(0.8-3.6)$ & & $1.3(0.6-2.9)$ & \\
\hline 5 and above & $27 / 264(10)$ & $5.0(2.4-10.5)$ & & $2.8(1.3-6.3)$ & \\
\hline \multicolumn{6}{|c|}{ Number of sex partners in the last 12 months } \\
\hline 1 & $50 / 1,685(3)$ & Ref & $<.01$ & & \\
\hline 2 and above & $25 / 268(9)$ & $3.4(2.0-5.5)$ & & & \\
\hline \multicolumn{6}{|c|}{ Primary sexual partner has other partners } \\
\hline Yes & $16 / 233(7)$ & $2.0(1.2-3.6)$ & .01 & & \\
\hline No & $60 / 1,724(4)$ & & & & \\
\hline \multicolumn{6}{|c|}{ Primary sexual partner has a new partner } \\
\hline Yes & $21 / 267(8)$ & $2.5(1.5-4.3)$ & $<.01$ & & \\
\hline No & $55 / 1,690(3)$ & Ref & & & \\
\hline \multicolumn{6}{|c|}{ Subjected to sexual violence in the past ${ }^{h}$} \\
\hline Yes & $8 / 134(6)$ & $1.6(0.8-3.5)$ & .20 & & \\
\hline No & $68 / 1,823(4)$ & Ref & & & \\
\hline \multicolumn{6}{|c|}{ Subjected to sexual violence recently ${ }^{i}$} \\
\hline Yes & $9 / 131(7)$ & $1.9(0.9-3.9)$ & .07 & & \\
\hline No & $67 / 1,826(4)$ & Ref & & & \\
\hline \multicolumn{6}{|c|}{ Committed sexual violence recently ${ }^{j}$} \\
\hline Yes & $7 / 48(15)$ & $4.6(1.9-10.5)$ & $<.01$ & $2.9(1.1-7.7)$ & .02 \\
\hline No & $69 / 1,909(4)$ & Ref & & Ref & \\
\hline
\end{tabular}


TABLE 3. Continued

\begin{tabular}{|c|c|c|c|c|c|}
\hline Characteristics & $\begin{array}{c}\text { Perpetrators of } \\
\text { IPV }^{\mathrm{c}} \mathrm{n} / \text { Row } \\
\text { Total (\%) }\end{array}$ & $\begin{array}{c}\text { Crude } \\
\text { Odds Ratio }^{d} \\
(95 \% \mathrm{Cl})\end{array}$ & PValue & $\begin{array}{l}\text { Adjusted } \\
\text { Odds Ratio } \\
(95 \% \mathrm{Cl})\end{array}$ & P Value \\
\hline \multicolumn{6}{|c|}{ Ever used a condom } \\
\hline Yes & $54 / 1,238(4)$ & $1.4(0.9-2.4)$ & .20 & & \\
\hline No & 22/719 (3) & Ref & & & \\
\hline \multicolumn{6}{|c|}{ Ever asked partner to use a condom } \\
\hline Yes & $49 / 995(5)$ & $1.8(1.1-2.9)$ & .02 & & \\
\hline No & $27 / 962(3)$ & Ref & & & \\
\hline \multicolumn{6}{|c|}{ Used a condom during last sexual intercourse } \\
\hline Yes & $35 / 842(4)$ & $1.1(0.7-1.8)$ & .80 & & \\
\hline No & $41 / 1,115(4)$ & & & & \\
\hline \multicolumn{6}{|c|}{ Experienced condom error in the last 3 months } \\
\hline Yes & $17 / 2,014(8)$ & $2.6(1.5-4.6)$ & $<.01$ & & \\
\hline No & $59 / 1,753(3)$ & Ref & & & \\
\hline \multicolumn{6}{|c|}{$\begin{array}{l}\text { Ever consumed alcohol before or during sex or } \\
\text { been drunk during sex }\end{array}$} \\
\hline Yes & $4 / 67(6)$ & $1.6(0.6-4.5)$ & .40 & & \\
\hline No & $72 / 1,890(4)$ & Ref & & & \\
\hline \multicolumn{6}{|c|}{$\begin{array}{l}\text { Partner ever consumed alcohol before or during } \\
\text { sex or been drunk during sex }\end{array}$} \\
\hline Yes & $5 / 77(6)$ & $1.8(0.7-4.5)$ & .20 & & \\
\hline No & $71 / 1,880$ (4) & Ref & & & \\
\hline \multicolumn{6}{|c|}{$\begin{array}{l}\text { Used drugs or mind-altering substances in the past } \\
\text { year }\end{array}$} \\
\hline Yes & $5 / 45(11)$ & $3.2(1.2-8.5)$ & .01 & & \\
\hline No & $71 / 1,912(4)$ & Ref & & & \\
\hline \multicolumn{6}{|c|}{$\begin{array}{l}\text { Partner used drugs or mind-altering substances in } \\
\text { the past year }\end{array}$} \\
\hline Yes & $1 / 51(2)$ & Ref & .50 & & \\
\hline No & $75 / 1,906(4)$ & $0.5(0.1-3.6)$ & & & \\
\hline
\end{tabular}

aParticipants were described as "perpetrators of IPV" if they answered in the affirmative to the question, 'Have you, in the last year, hit, slapped, kicked, or done anything else to physically hurt any of your sexual partners?'

bResponses missing for 2 participants who did not answer questions about ever having perpetrated physical IPV.

There were $77(4 \%)$ perpetrators of IPV; the numerators in this column are the number of perpetrators of IPV who fulfilled the criteria described in the respective rows, and the denominators are the total number of participants who fulfilled the criteria mentioned in each row.

${ }^{\mathrm{d}}$ Crude odds ratios refer to the odds of an outcome given the response status of a particular variable.

eAdjusted odds ratios are crude odds ratios adjusted after considering the influence of all other variables.

Includes 32 participants who were either divorced or widowed.

gResponses missing for 135 participants.

hParticipants were characterised as having ever been subjected to "sexual violence in the past" if they answered "yes" to the question, 'Have you ever been forced to have sex?'

'Participants were characterised as having been subjected to "sexual violence recently" if they answered in the affirmative to the question, 'In the last

12 months has partner $X$ forced you to have sex?'

"Participants were characterised as having committed "sexual violence recently" if they answered "yes" to the question, "In the last 12 months have you forced any of your sex partners to have sex?'

Abbreviations: $\mathrm{Cl}$, confidence interval; IPV, intimate partner violence. 


\section{Limitations}

This study's limitations included the sole focus on physical violence without consideration of sexual or psychological forms of IPV. This analysis was also limited by recall and respondent biases; participants may have felt embarrassed to admit to the interviewers that they had been subjected to or had perpetrated IPV. For these reasons, our estimates of the burden of IPV in this population may be underestimated.

\section{RECOMMENDATIONS AND CONCLUSION}

There was a high prevalence of IPV among sexually active youth in this rural community. Study participants were recurrent victims or perpetrators and reported behaviours that put them at risk of HIV acquisition. Victims and perpetrators also possessed characteristics that could be used by screening programmes to identify and target them for specific interventions.

There is a need to reduce gender inequality and to enhance the livelihoods of young women via upstream interventions. The Ministry of Health in Kenya provides structural prevention approaches to bolster resilience among women and girls through behavioural interventions, including evidence-based behavioural HIV prevention strategies to equip young girls with the skills to negotiate safe sex. The Ministry also conducts targeted sensitisation about IPV, for example, in conjunction with the United States Agency for International Development and the Determined, Resilient, Educated, AIDS-free, Mentored, and Safe (DREAMS) mentorship programme for adolescents and young women. ${ }^{30}$

Downstream interventions to address IPV could include screening and provision of gender-based violence and recovery centres and services. Health-care workers should also screen for other forms of IPV among women presenting to health-care facilities with physical injuries, depression symptoms, and miscarriages, or for routine care. ${ }^{31}$ The potential benefits of health-care screening programmes rely on client expectations of compassionate, nonjudgemental, and effective care delivery from health-care providers. $^{32}$ If this is accomplished, health workers can provide appropriate referrals to further reduce exposure to IPV and its consequences. ${ }^{32}$ Fragmented care has been identified as a barrier to effective management of IPV. Because gender-based violence services are not routinely offered as part of standard care, victims of IPV are often lost along the referral cascade. Gender-based violence services should, therefore, be diversified to include legal services and professional counselling in addition to health services. ${ }^{22}$ There should also be clear laws related to IPV to enhance legal reporting and clear guidelines on the management of all forms of IPV - not just physical violence. $^{33}$

Health-care programmes should also publicise the availability of gender-based violence and recovery services to both health-care providers and communities to encourage reporting of IPV. Information campaigns have been shown to enhance clients' perspectives on the availability of facilities to assist victims of IPV. ${ }^{34}$ Furthermore, community mobilisation of gender-based violence service campaigns in Kisumu County, Kenya, led to an increase in the number of cases that were seen at the gender-based violence centre there (HIV Prevention Coordinator, KEMRI Centre for Global Health Research, personal communication, 12 June 2014).

Several integrated approaches can be used to prevent IPV. Upstream approaches include legislation to deter potential offenders and punish reported offenders. ${ }^{33}$ Policy makers should enforce existing legislation, such as the Sexual Offences Act in the Constitution of Kenya, which will deter potential perpetrators of IPV and reprimand identified perpetrators. ${ }^{35}$ Policy makers also ought to address other determinants of IPV, including poverty, drug abuse, economic dependency on men by victims of IPV, and societal norms. The provision of life skills training to address known risk factors for perpetrating IPV - such as alcoholism and unemployment - and the use of renowned male role models as ambassadors against IPV, would also contribute to preventing IPV. ${ }^{6,36}$

Upon identification of IPV perpetrators, downstream interventions should include needs and risk assessments of the perpetrators and their immediate family environments. The findings of such evaluations should then be incorporated into programmes to motivate the perpetrators to change their maladaptive behaviours. ${ }^{37}$ Perpetrators should also enrol in batterer intervention programmes. ${ }^{38}$ In the United States, a second responder intervention focused on assessed police outcomes of previous perpetrators randomised to an intervention group that provided risk profiling, interventions based on men's criminogenic triggers, and responsivity. Compared to a control group, men in the intervention group reported lower rates of domestic violence. ${ }^{25}$ This exemplified the effectiveness of interventions that are tailored to the learning styles and motivations of intervention participants. As more than one-tenth of perpetrators reported having ever committed sexual violence recently in our evaluation, there is a need for targeted interventions. Communities should be sensitised to the dangers of IPV and other means of improving communication and conflict resolution within partnerships. $^{30}$

In 2010, voluntary HIV counselling and testing centres were proposed as ideal places to identify victims of IPV, because these centres offer opportunities to discuss risky sexual behaviour and HIV prevention. ${ }^{24}$ However, without adequate skills to discuss gender inequality issues, lay counsellors conducting screening for IPV were unable to offer solutions. ${ }^{39}$ In response to this, in 2014, a couples HIV riskreduction programme implemented by South African community health centre workers achieved IPV reduction over a period of 1 year. ${ }^{40}$ Couples counselling and testing would, therefore, be an ideal setting to broach the issue of IPV in the context of HIV risk reduction counselling and HIV testing. 
Further research is required to assess the proportion of IPV incidents that are reported, quantify the burden of IPV (including other forms of violence in the definition of IPV), determine the motivating and contributing factors behind IPV, and assess the impact of any programmes that address IPV perpetrators.

Acknowledgements: We wish to acknowledge the participants, the KEMRI HISS and HIV-R staff, KEMRI Director, CDC, and the Ministry of Health in Kenya for their contributions to this evaluation. This publication was made possible by support from the US President's Emergency Plan for AIDS Relief (PEPFAR), through cooperative agreement No. 5U19GH000041, from the US Centers for Disease Control and Prevention (CDC), Division of Global HIV/AIDS (DGHA) and Division of HIV/AIDS Prevention (DHAP).

\section{REFERENCES}

1. World Health Organization (WHO). HIV/AIDS: key facts. WHO Website http://www.who.int/news-room/fact-sheets/detail/hiv-aids. Accessed 10 October 2018

2. Joint United Nations Programme on HIV/AIDS (UNAIDS). Fact Sheet: Adolescents, Young People, and HIV. Geneva: UNAIDS; 2012. http://files.unaids.org/en/ media/unaids/contentassets/documents/factsheet/2012/20120417_FS_ adolescentsyoungpeoplehiv_en.pdf. Accessed 10 October 2018.

3. World Health Organization (WHO). Facts: Intimate Partner Violence. Geneva: WHO; 2002. http://www.who.int/violence_injury_prevention/violence/world_ report/factsheets/en/ipvfacts.pdf. Accessed 10 October 2018.

4. Norris SM, Huss MT, Palarea RE. A pattern of violence: analyzing the relationship between intimate partner violence and stalking. Violence Vict. 2011;26(1):103115. CrossRef. Medline

5. Li Y, Marshall CM, Rees HC, Nunez A, Ezeanolue EE, Ehiri JE. Intimate partner violence and HIV infection among women: a systematic review and meta-analysis. J Int AIDS Soc. 2014;17(1):18845. CrossRef. Medline

6. World Health Organization (WHO). Understanding and Addressing Violence Against Women: Intimate Partner Violence. Geneva: WHO; 2012. http://apps. who.int/iris/bitstream/handle/10665/77432/WHO_RHR_12.36_eng.pdf? sequence=1. Accessed 10 October 2018.

7. Henderson L, Zerai A, Morrow RL. Intimate partner violence and HIV status among ever-married and cohabiting Zimbabwean women: an examination of partners' traits. Afr J Reprod Health. 2017;21(4):45-54. CrossRef. Medline

8. Etudo O, Metheny N, Stephenson R, Kalokhe AS. Intimate partner violence is linked to less HIV testing uptake among high-risk, HIV-negative women in Atlanta. AIDS Care. 2017;29(8):953-956. CrossRef. Medline

9. Mendoza C, Barrington C, Donastorg Y, et al. Violence from a sexual partner is significantly associated with poor HIV care and treatment outcomes among female sex workers in the Dominican Republic. J Acquir Immune Defic Syndr. 2017;74(3):273278. CrossRef. Medline

10. National AIDS Control Council (NACC), National AIDS and STI Control Programme (NASCOP). Kenya HIV County Profiles 2016. Nairobi, Kenya: NACC and NASCOP; 2016. https://nacc.or.ke/wp-content/uploads/2016/12/Kenya-HIVCounty-Profiles-2016.pdf. Accessed 10 October 2018.

11. Kose J, Tiam A, Ochuka B, et al. Impact of a comprehensive adolescent-focused case finding intervention on uptake of $\mathrm{HIV}$ testing and linkage to care among adolescents in Western Kenya. J Acquir Immune Defic Syndr. 2018;79(3):367-374. CrossRef. Medline

12. Odhiambo FO, Laserson KF, Sewe M, et al. Profile: The KEMRI/CDC Health and Demographic Surveillance System -Western Kenya. Int J Epidemiol. 2012; 41(4):977-987. CrossRef. Medline

13. Burmen B, Mutai K. Coverage, perceptions and desire for male circumcision in a traditionally non-circumcising Kenyan community in Western Kenya, 2013-2014. Afr J Health Sci. 2016;29(3).

14. United Nations Department of Economic and Social Affairs (UNDESA). Definition of Youth. New York: UNDESA; 2013. http://www.un.org/esa/socdev/ documents/youth/fact-sheets/youth-definition.pdf. Accessed 11 October 2018.

15. Phillips-Howard PA, Otieno G, Burmen B, et al. Menstrual needs and associations with sexual and reproductive risks in rural Kenyan females: a cross-sectional behavioral survey linked with HIV prevalence. J Womens Health (Larchmt). 2015; 24(10):801-811. CrossRef. Medline

16. Jewkes R. Intimate partner violence: causes and prevention. Lancet. 2002;359 (9315): 1423-1429. CrossRef. Medline

17. Bruce N, Pope D, Stanistreet D. Quantitative Methods for Health Research: A Practical Interactive Guide to Epidemiology and Statistics. Chichester, UK: John Wiley \& Sons; 2008.

18. National Bureau of Statistics, ICF International. Kenya Demographic and Health Survey 2014. Nairobi, Kenya, and Rockville, MD, USA: National Bureau of Statistics and ICF International; 2015.

19. Gass JD, Stein DJ, Williams DR, Seedat S. Gender differences in risk for intimate partner violence among South African adults. J Interpers Violence. 2011; 26(14):2764-2789. CrossRef. Medline

20. Field S, Onah M, van Heyningen T, Honikman S. Domestic and intimate partner violence among pregnant women in a low resource setting in South Africa: a facility-based, mixed methods study. BMC Womens Health. 2018;18(1):119. CrossRef. Medline

21. Sabri B, Renner LM, Stockman JK, Mittal M, Decker MR. Risk factors for severe intimate partner violence and violence-related injuries among women in India. Women Health. 2014;54(4):281-300. CrossRef. Medline

22. Institute of Medicine, National Research Council. Preventing Intimate Partner Violence in Uganda, Kenya, and Tanzania: Summary of a Joint Workshop by the Institute of Medicine, the National Research Council, and the Uganda National Academy of Sciences. Washington, DC: The National Academies Press; 2015. https://www.ncbi.nlm.nih.gov/books/NBK310335/. Accessed 11 October 2018.

23. Kwagala B, Wandera SO, Ndugga P, Kabagenyi A. Empowerment, partner's behaviours and intimate partner physical violence among married women in Uganda. BMC Public Health. 2013;13:1112. CrossRef. Medline

24. National AIDS and STI Control Programme (NASCOP), Ministry of Health [Kenya] The Kenya HIV Testing Services Guidelines. 3rd ed. Nairobi, Kenya: NASCOP; 2015. https://aidsfree.usaid.gov/sites/default/files/hts_policy_kenya_2015.pdf. Accessed 11 October 2018.

25. Scott K, Heslop L, Kelly T, Wiggins K. Intervening to prevent repeat offending among moderate- to high-risk domestic violence offenders: a second-responder program for men. Int J Offender Ther Comp Criminol. 2015;59(3):273-294. CrossRef. Medline

26. Burgos-Soto J, Orne-Gliemann J, Encrenaz G, et al. Intimate partner sexual and physical violence among women in Togo, West Africa: prevalence, associated factors, and the specific role of HIV infection. Glob Health Action. 2014;7(1):23456. CrossRef. Medline

27. Zembe YZ, Townsend L, Thorson A, Silberschmidt M, Ekstrom AM. Intimate partner violence, relationship power inequity and the role of sexual and social risk factors in the production of violence among young women who have multiple sexual partners in a peri-urban setting in South Africa. PLoS One. 2015;10(11):e0139430. CrossRef. Medline

28. Teitelman AM, Tennille J, Bohinski J, Jemmott LS, Jemmott JB III. Urban adolescent girls' perspectives on multiple partners in the context of the sexual double standard and intimate partner violence. J Assoc Nurses AIDS Care. 2013;24(4):308-321. CrossRef. Medline

29. Purdie MP, Abbey A, Jacques-Tiura AJ. Perpetrators of intimate partner sexual violence: are there unique characteristics associated with making partners have sex without a condom? Violence Against Women. 2010;16(10):1086-1097. CrossRef. Medline

30. National AIDS and STI Control Programme (NASCOP), Ministry of Health; National AIDS Control Council (NACC) [Kenya]. Kenya HIV Prevention Revolution Road Map: Count Down to 2030. Nairobi, Kenya: NASCOP and NACC; 2015. https:// hivhealthclearinghouse.unesco.org/sites/default/files/resources/kenya_hiv_ prevention_revolution_road_map.pdf. Accessed 11 October 2018. 
31. Tanimu TS, Yohanna S, Omeiza SY. The pattern and correlates of intimate partner violence among women in Kano, Nigeria. Afr J Prim Health Care Fam Med. 2016;8(1):el-e6. CrossRef. Medline

32. Chen C, Greb A, Kalia I, Bajaj K, Klugman S. Patient perspectives on intimate partner violence discussion during genetic counseling sessions. J Genet Couns. 2017; 26(2):261-271. CrossRef. Medline

33. Nguyen QP, Flynn N, Kitua $M$, et al. The health care sector response to intimate partner violence in Kenya: exploring health care providers' perceptions of care for victims. Violence Vict. 2016;31(5):888-900. CrossRef. Medline

34. Madden K; for PREVAlL Investigators. An intimate partner violence informational program in a hospital fracture clinic: a pre-test post-test intervention study. J Inj Violence Res. 2017;9(1):7-15. CrossRef. Medline

35. The Republic of Kenya. Constitution of Kenya, 2010. Nairobi, Kenya: National Council for Law Reporting; 2010. http://kenyalaw.org/lex/rest/db/kenyalex/ Kenya/The\%20Constitution\%20of\%20Kenya/docs/ConstitutionofKenya\%202010. pdf. Accessed 12 October 2018.

36. Gilchrist $G$, Hegarty K. Tailored integrated interventions for intimate partner violence and substance use are urgently needed. Drug Alcohol Rev. 2017;36(1):3-6. CrossRef. Medline

37. Crane CA, Easton CJ. Integrated treatment options for male perpetrators of intimate partner violence. Drug Alcohol Rev. 2017;36(1):24-33. CrossRef. Medline

38. Eckhardt Cl, Murphy C, Black D, Suhr L. Intervention programs for perpetrators of intimate partner violence: conclusions from a clinical research perspective. Public Health Rep. 2006;121(4):369-381. CrossRef. Medline
39. Christofides N, Jewkes R. Acceptability of universal screening for intimate partner violence in voluntary HIV testing and counseling services in South Africa and service implications. AIDS Care. 2010;22(3):279-285. CrossRef. Medline

40. Jones D, Weiss SM, Arheart K, Cook R, Chitalu N. Implementation of HIV prevention interventions in resource limited settings: the partner project. J Community Health. 2014;39(1):151-158. CrossRef. Medline

\section{Peer Reviewed}

Competing Interests: None declared.

Received: 11 May 2018; Accepted: 4 Oct 2018

Cite this article as: Burmen B, Olilo G, Makanga EM. Victims and Perpetrators of Intimate Partner Violence Among Sexually Active Youth in a Community With a High HIV Prevalence in Western Kenya. East African Health Res J. 2018;2(2):79-90. https://doi.org/10.24248/EAHRJ-D-18-00019

(C) Burmen et al. This is an open-access article distributed under the terms of the Creative Commons Attribution License, which permits unrestricted use, distribution, and reproduction in any medium, provided the original author and source are properly cited. To view a copy of the license, visit http://creativecommons.org/licenses/by/4.0/. When linking to this article, please use the following permanent link: https://doi.org/ 10.24248/EAHRJ-D-18-00019 